\title{
Autoantibodies to central nervous system neuronal surface antigens: psychiatric symptoms and psychopharmacological implications
}

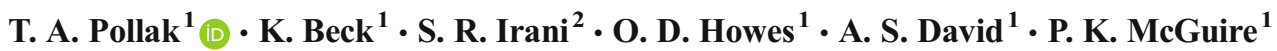

Received: 9 September 2015 / Accepted: 5 November 2015 /Published online: 14 December 2015

(C) The Author(s) 2015. This article is published with open access at Springerlink.com

\begin{abstract}
Rationale Autoantibodies to central nervous system (CNS) neuronal surface antigens have been described in association with autoimmune encephalopathies which prominently feature psychiatric symptoms in addition to neurological symptoms. The potential role of these autoantibodies in primary psychiatric diseases such as schizophrenia or bipolar affective disorder is of increasing interest.

Objectives We aimed to review the nature of psychiatric symptoms associated with neuronal surface autoantibodies, in the context of autoimmune encephalopathies as well as primary psychiatric disorders, and to review the mechanisms of action of these autoantibodies from a psychopharmacological perspective.

Results The functional effects of the autoantibodies on their target antigens are described; their clinical expression is at least in part mediated by their effects on neuronal receptor function, primarily at the synapse, usually resulting in receptor hypofunction. The psychiatric effects of the antibodies are related to known functions of the receptor target or its complexed proteins, with reference to supportive genetic and pharmacological evidence where relevant. Evidence for a causal role of these autoantibodies in primary psychiatric disease is increasing but remains controversial; relevant methodological
\end{abstract}

A.S. David and P.K. McGuire are joint supervising authors.

T. A. Pollak

thomas.pollak@kcl.ac.uk

1 Department of Psychosis Studies, Institute of Psychiatry, Psychology and Neuroscience, King's Health Partners, King's College London, De Crespigny Park, Denmark Hill, London SE5 8AF, UK

2 Nuffield Department of Clinical Neurosciences, John Radcliffe Hospital, Oxford, UK controversies are outlined. Non-receptor-based mechanisms of autoantibody action, including neuroinflammatory mechanisms, and therapeutic implications are discussed.

Conclusions An analysis of the autoantibodies from a psychopharmacological perspective, as endogenous, bioactive, highly specific, receptor-targeting molecules, provides a valuable opportunity to understand the neurobiological basis of associated psychiatric symptoms. Potentially, new treatment strategies will emerge from the improving understanding of antibody-antigen interaction within the CNS.

Keywords Antibody · Immunoreactivity $\cdot$ Inflammation · Receptor $\cdot$ NMDA receptor $\cdot$ Potassium channel $\cdot$ GABA receptor $\cdot$ Limbic system

\section{Introduction}

Over the last decade, there has been an increasing recognition of central nervous system (CNS) syndromes associated with autoantibodies to CNS cell surface antigens ('neuronal surface autoantibodies' or 'NSAbs'). The majority of these syndromes feature prominent psychiatric and cognitive symptoms, amongst manifold neurological manifestations such as seizures, movement disorders and autonomic dysfunction and are best described as 'autoimmune encephalopathies'. Recognition of these syndromes and research on the mechanisms of action of their associated, and likely pathogenic, antibodies has had a huge impact on clinical neurology and an increasing influence on psychiatry as well.

Given the almost universal occurrence of psychiatric and cognitive symptoms in these autoimmune encephalopathies, NSAbs are of considerable interest to researchers studying the neurobiological bases of psychiatric symptoms. In recent years, the possibility that NSAbs can cause a 'purely 
psychiatric' phenotype has been the object of interest, partly because of the implication that were this to be the case at least a subset of what is currently termed primary psychiatric disease may in fact be NSAb-mediated and potentially respond to treatment with immunotherapies (Deakin et al. 2014) (Table 1).

\section{Technical developments}

The methodology that has facilitated the last decade's rapid increase in research has been the development of cell-based assays (CBAs) using human embryonic kidney (HEK) cells that have been transfected to express the antigen of interest on their surface (Rodriguez Cruz et al. 2015). These assays have a number of advantages over the immunoassays that preceded CBAs, such as enzyme-linked immunosorbent assay (ELISA) or radioimmunoassay (RIA). Firstly, the antigenic target is presented in its native conformation at the cell surface: antibodies which target such proteins are likely to operate in vivo. Secondly, antibodies that can be demonstrated to target extracellular antigens are likely to be pathogenic (Graus and Dalmau 2012). Not surprisingly, therefore, the disorders associated with NSAbs detectable via CBAs, unlike those associated with the classical intracellularly directed onconeural antibodies, tend to be immunotherapy-responsive, with sometimes even the most acutely unwell patients making a substantial or even complete recovery following immunotherapy (Kayser et al. 2013).

\section{The patient's autoantibodies as pseudo-pharmacological agents: a new paradigm in psychopharmacology}

NSAbs form a unique class in that their clinical expression is at least in part mediated by their effects on neuronal receptor function, primarily at the synapse; usually, this results in receptor hypofunction (see Table 2). Although these effects are not thought to occur primarily via direct action of the antibody at the receptor, as is the case with psychotropic drugs, this general mechanism of action invites an analysis of the antibodies from a pharmacological perspective, as endogenous, bioactive, highly specific, receptor-targeting molecules. This concept builds on the established notion of an 'autoimmune channelopathy'; but while some NSAbs do target ion channels (e.g. $N$-methyl-D-aspartate receptor [NMDAR], $\alpha$-amino-3hydroxy-5-methyl-4-isoxazole propionic acid receptor [AMPAR], $\gamma$-aminobutyric acid receptor [GABAR]), it should be noted that others are specific for receptorassociated or regulatory molecules (e.g. contactin-associated protein-like 2 [CASPR2], leucine-rich glioma inactivated 1 [LGI1], dipeptidyl-peptidase-like protein-6 [DPPX]) or metabotropic cell surface receptors (e.g. dopamine D2 receptor [D2R], metabotropic glutamate receptor 5 [mGluR5]). Mutations in many of these proteins have been linked to neuropsychiatric conditions, strengthening the likelihood of antibody pathogenicity (Irani et al. 2014).

This review will focus on those CNS-directed NSAbs that have been associated with clinical syndromes which feature prominent psychiatric features. Some NSAbs have been more consistently associated with a particular disease phenotype than others, although with the passage of time, the number of conditions in which all NSAbs have been identified continues to increase (Irani et al. 2014).

The neurological signs and symptoms associated with NSAbs have been given less focus in this article to make space for discussion of psychiatric phenomena; we would direct readers to the article by Varley and colleagues (Varley et al. 2015) for a more neurologically focussed review.

\section{$\mathrm{N}$-methyl-D-aspartate (NMDA) receptor antibodies}

IgG antibodies to the extracellular N-terminal domain of the NR1 subunit of the NMDAR are associated with NMDAR antibody encephalitis. First described in 2007 in young women presenting with neuropsychiatric symptoms in the presence of an ovarian teratoma (Dalmau et al. 2007), NMDAR encephalitis has a characteristic progression, frequently involving a viral prodrome followed by two phases of illness. The early phase includes psychiatric symptoms, cognitive dysfunction and seizures, progressing later to movement disorder, dysautonomia and coma (Irani et al. 2010a). NMDAR antibody encephalitis is increasingly described in older patients, patients without tumours, men and children (Titulaer et al. 2013).

\section{The nature of psychiatric symptoms associated with NMDAR NR1-directed antibodies}

NMDAR antibodies are of particular interest in psychiatric research, as approximately $80 \%$ of adults with NMDAR antibody encephalitis initially present with behavioural and psychiatric symptoms (Kayser et al. 2013). Changes in mood, behaviour or personality are also common early features in children and adolescents. Symptoms can include anxiety, agitation, bizarre behaviour, catatonia, delusional or paranoid thoughts and visual or auditory hallucinations, accompanied by memory loss (Irani et al. 2010a). It has been recognised that a minority of individuals only present with one or few symptoms, usually psychosis or seizures (Kayser et al. 2013; Niehusmann et al. 2009). This raises the possibility of a partial or attenuated syndrome, with a predominance of psychotic symptoms, accompanied by few or no other clinical characteristics of NMDAR antibody encephalitis.

An observational study by Kayser et al. found $4 \%$ of cases of NMDAR antibody encephalitis presented with isolated psychiatric symptoms. This rose to $28 \%$ of a group 


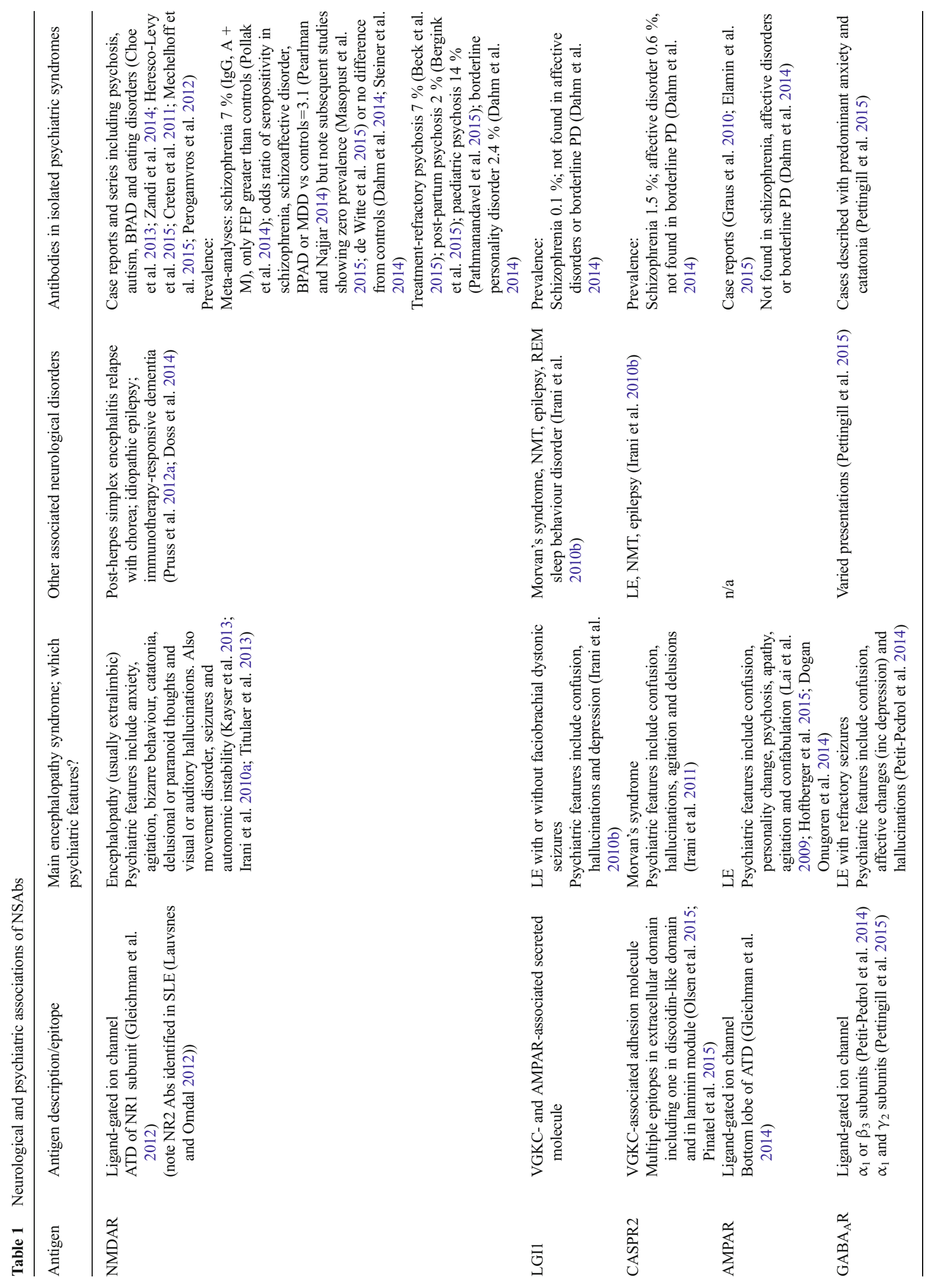




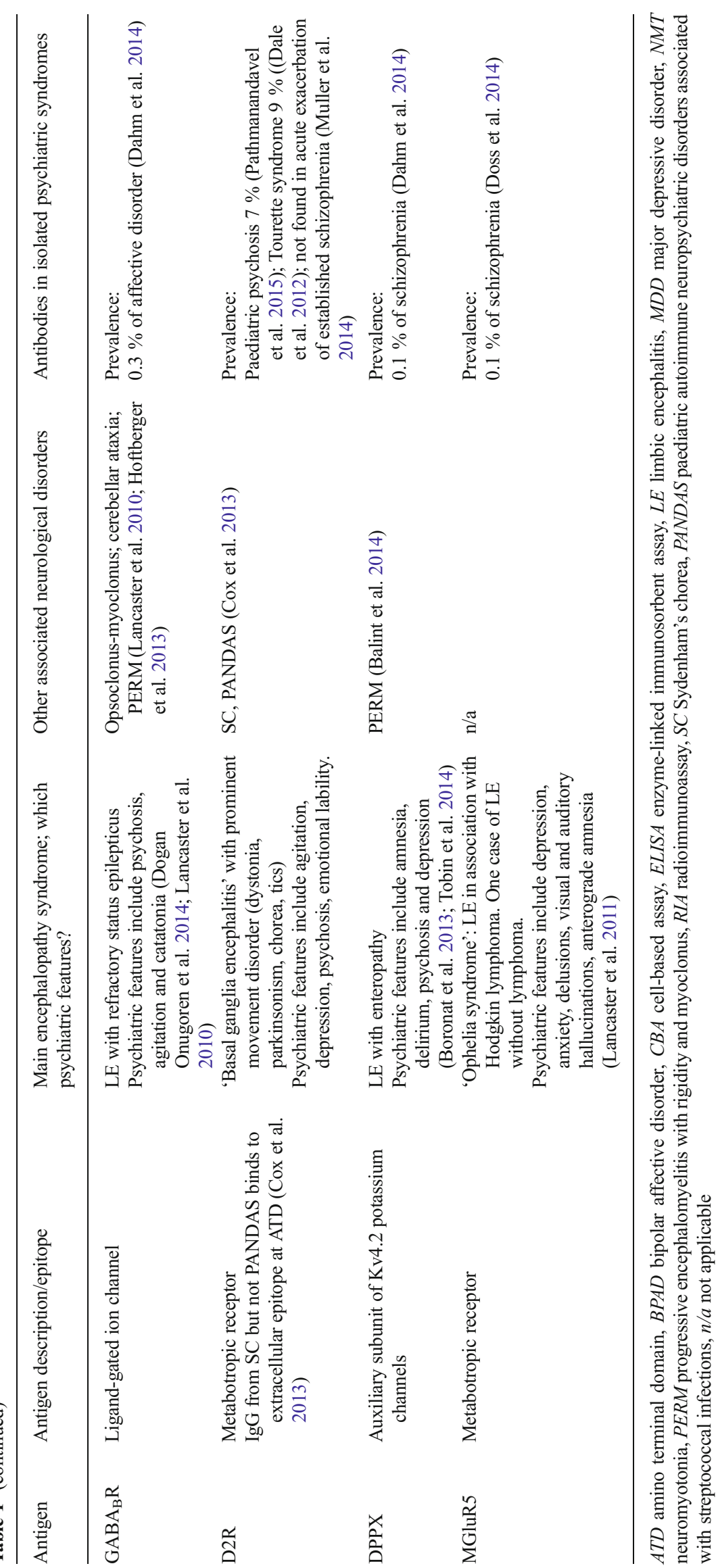




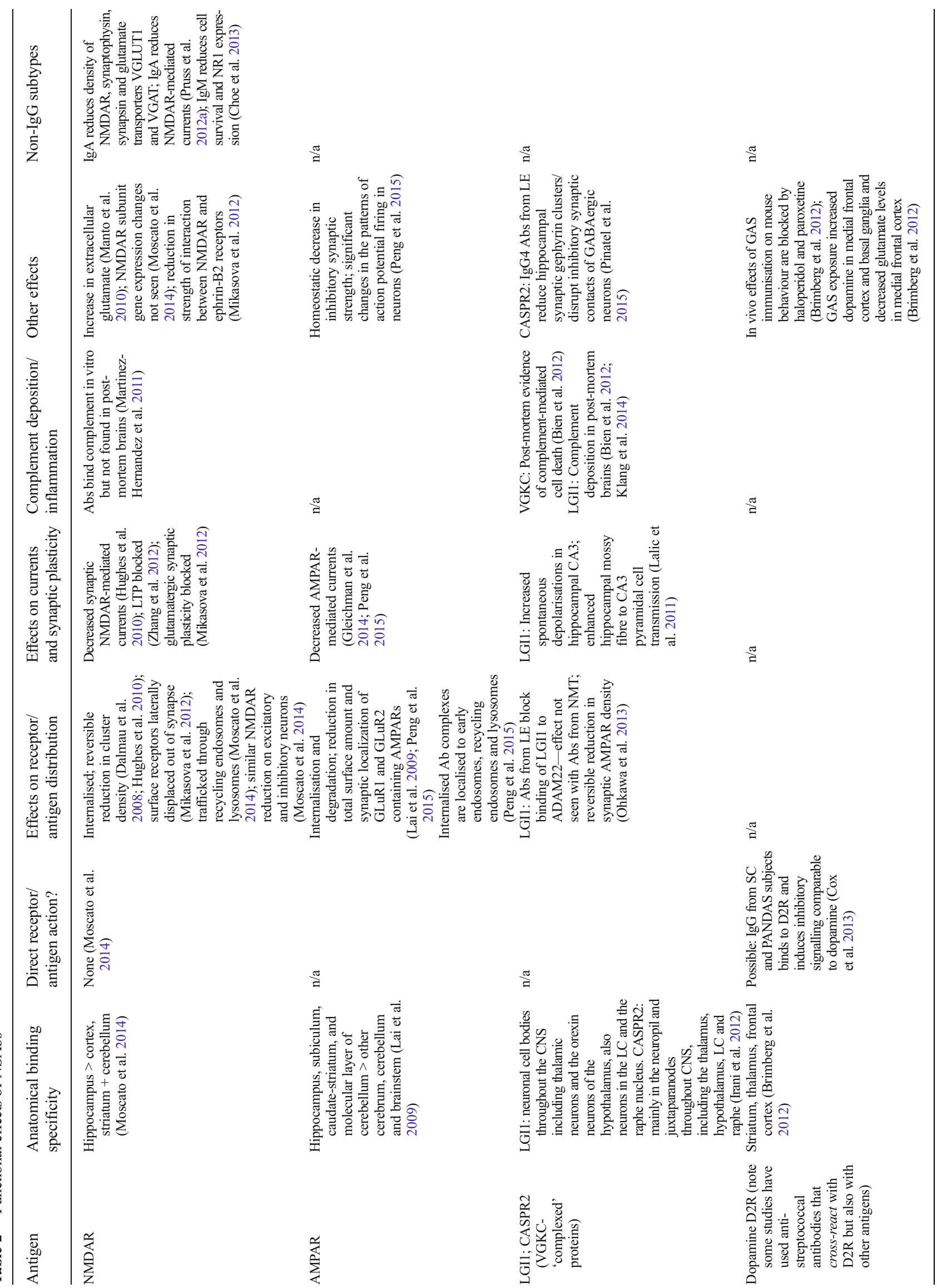


experiencing relapses. Seventy-four percent had delusional thoughts, $43 \%$ had auditory or visual hallucinations and $57 \%$ had aggressive behaviour. Seventy percent had a mood component to their presentation including mania, mood lability, impulsivity, disinhibition and depressive or nonspecific mood changes (Kayser et al. 2013). The clinical picture has broadened further with a recent study finding $2 \%$ of cases of post-partum psychosis had NMDAR antibodies (Bergink et al. 2015).

\section{Effects of immunotherapy}

Most patients with a diagnosis of NMDAR antibody encephalitis experience a substantial improvement in their symptoms when treated with immunotherapy (first line: steroids, intravenous immunoglobulin (IVIg), plasma exchange; second line: rituximab, cyclophosphamide) and/or tumour removal (Titulaer et al. 2013), with early treatment a predictor of a good outcome (Kayser et al. 2013). Nevertheless, a majority of patients experience persistent subjective cognitive deficits or have deficits on cognitive testing including memory impairment and executive dysfunction (Finke et al. 2012). Memory deficits correlate with hippocampal damage on MR imaging, the extent of which is predicted by disease severity and duration, highlighting the importance of early diagnosis and appropriate treatment (Finke et al. 2012, 2015).

\section{Potential mechanisms underlying the psychiatric effects of NMDAR N1 antibodies}

Of all NSAbs, the mechanisms underlying the effects of NMDAR NR1 antibodies have been most extensively investigated and mimic many of the mechanisms established originally in the study of pathogenic antibodies directed against the acetylcholine receptor in myasthenia gravis, the prototypical antibody-mediated neurological disorder. Although the epitope is located within the N-terminus that also contains the glycine binding site, it has been demonstrated that NMDAR antibodies do not have a direct action at the receptor (Moscato et al. 2014). Rather they cause a reversible, timeand dose-dependent internalisation of cell membrane-bound NMDARs with a subsequent decrease in synaptic and extrasynaptic receptor density and a reduction in NMDARmediated currents and synaptic plasticity (Fig. 1 and Table 2).

Glutamate dysfunction, in particular NMDAR hypofunction, is thought to be central to the pathophysiology of schizophrenia (Howes et al. 2015). NMDAR antagonists such as phencyclidine (PCP) and ketamine are able to induce psychotic and cognitive symptoms resembling those seen in psychotic disorders (Javitt 2007) and are similar to those described in NMDAR antibody encephalitis. Furthermore, PCP can stimulate agitation and dissociative states including reduced responsiveness with catatonic features (Javitt and Zukin 1991), well-described in NMDAR 
Fig. 1 Potential mechanisms of action of NSAbs. Specific NSAbs represented here are examples only and multiple mechanisms may be shared by different NSAbs. Note that NSAbs are likely to have relevant downstream effects on intraneuronal signalling, compensatory changes in the expression of other surface proteins and effects on largerscale neuronal network function. Figure reproduced with kind permission from Varley et al. (Varley et al. 2015)

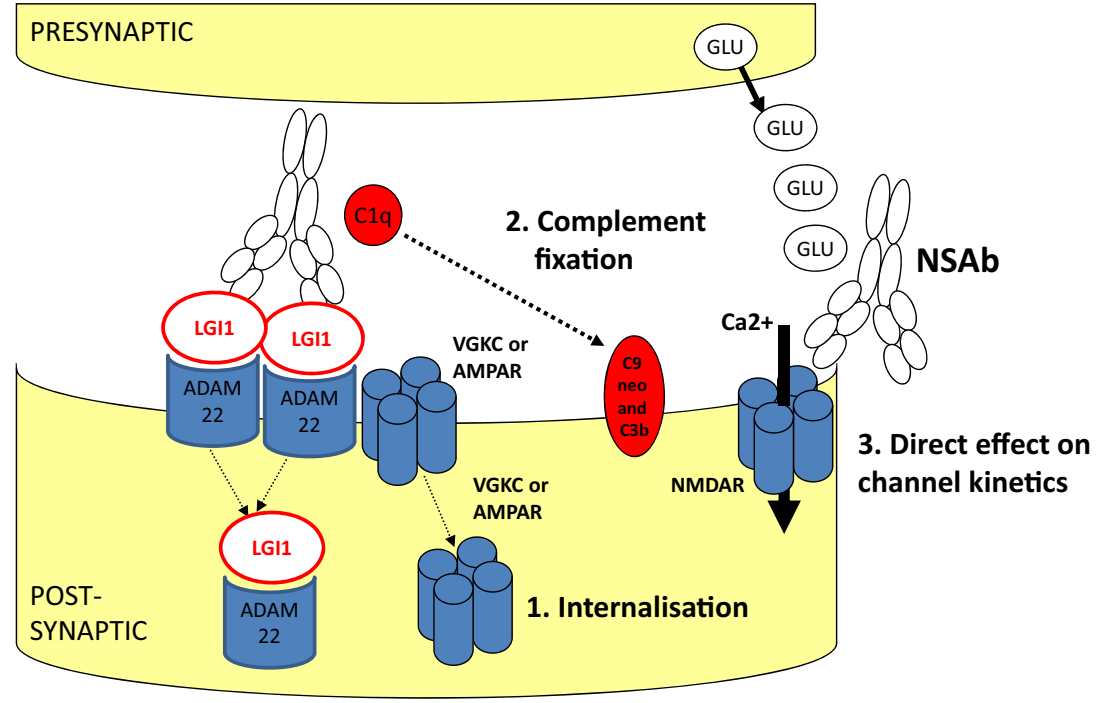

antibody encephalitis. NMDAR antibodies also cause an increase in extracellular glutamate (Manto et al. 2010), an effect directly comparable to that of the non-competitive NMDAR antagonist ketamine (Liu and Moghaddam 1995). The psychotic symptoms associated with ketamine use are directly linked to cortical glutamate levels (Stone et al. 2012), suggesting that this could also be a mechanism by which NMDAR antibodies cause psychosis.

Partial NR1 knockout mice display schizophrenia-related behaviours, including cognitive impairment (Belforte et al. 2010). Multiple genes associated with schizophrenia are related to the NMDAR and associated synaptic proteins (Hall et al. 2015; Kirov et al. 2012; Timms et al. 2013). Post-mortem data provide evidence for abnormalities in the NMDAR in patients with schizophrenia (Rubio et al. 2012). There is also in vivo evidence for reduced NMDAR in the hippocampus of unmedicated patients with schizophrenia (Rubio et al. 2012; Pilowsky et al. 2006). Furthermore, there is some limited evidence that drugs modulating the NMDAR are effective in schizophrenia (Stone 2011).

Planaguma and colleagues developed an animal model of NMDAR encephalitis in which patient CSF IgG was administered to mice via intraventricular infusion over 14 days. The mice had memory impairments, anhedonia and depressive behaviour, but there were no effects on anxiety or locomotor activity (Planaguma et al. 2015). From the neuropsychiatric perspective, while this model shows clear in vivo effects of NMDAR antibodies, it does not provide a good fit with the phenomenology of NMDAR antibody encephalitis, a condition frequently characterised by agitation, anxiety and affective lability or even mood elevation. Further, despite psychosis being the most common psychiatric feature, the authors did not assess effects on paradigms used in animal models of psychosis. Given the absence of any clear epileptic seizures, autonomic dysfunction or movement disorders in the mice, it is also unclear how valid a model this is of NMDAR antibody encephalitis more broadly.

\section{Other NMDAR antibodies}

NMDAR NR2 antibodies, as detected using ELISA, have been implicated in neuropsychiatric systemic lupus erythematosus (SLE) (Lauvsnes and Omdal 2012), where they have also been associated with a reduction in hippocampal volume (Lauvsnes et al. 2014). No published work to date has addressed whether there is overlap between the antibodies in this population and with the NR1 antibodies implicated in NMDAR encephalitis, but the detection methods are sufficiently different to suggest no overlap exists.

More recently, neuropsychiatric presentations have also been associated with IgA and IgM NMDAR antibodies. NMDAR IgA and IgM antibodies have been found in patients with progressive cognitive dysfunction and dementia (Pruss et al. 2012a; Doss et al. 2014), and IgM antibodies have been identified in cases of bipolar affective disorder and psychosis (Choe et al. 2013; Hammer et al. 2014). These studies also provide growing evidence for their pathogenicity in vitro, but this is not as robust as for the IgG subtype. However, their presence in the CSF of some patients may suggest that they have pathogenic potential (Doss et al. 2014).

\section{Voltage-gated potassium channel (VGKC) complex antibodies}

Initially described in association with peripheral nerve hyperexcitability, antibodies that immunoprecipitated the alphadentrotoxin-sensitive VGKC alpha subunits were soon (Liguori et al. 2001) recognised in Morvan's syndrome, a condition featuring both peripheral nerve and neuropsychiatric 
symptoms including anxiety, obsessional behaviour, sleepwake disruption and psychosis (Irani et al. 2012). Limbic encephalopathy in association with VGKC complex antibodies was first described in 2001 (Buckley et al. 2001). Memory deficits, disorientation and medial temporal lobe seizures predominate, although psychiatric symptoms are often present and may occasionally be the presenting feature (Thieben et al. 2004). Psychiatric symptoms include, in order of decreasing frequency, personality change, depression, anxiety, visual hallucinations, spells and delusions (Somers et al. 2011). Sleep abnormalities are common (Cornelius et al. 2011).

Some patients with VGKC complex antibody-associated encephalopathies present initially to psychiatric services, although this proportion is smaller than in NMDAR encephalitis. Patients with VGKC complex antibodies tend to be older than those with NMDAR antibodies (Paterson et al. 2014). In addition to the prominence of cognitive and psychiatric symptoms, a number of cases have now been described in which VGKC complex antibodies have been associated with a predominantly psychiatric phenotype, usually comprising a schizophreniform or more polymorphic psychosis with varying degrees of cognitive deficit (Somers et al. 2011; Zandi et al. 2011; Parthasarathi et al. 2006; Tang et al. 2015), although it is unclear whether this includes cases in which the antibodies are causally relevant (see below) (Paterson et al. 2014).

\section{Antibodies to VGKC-'complexed' proteins}

VGKC complex antibodies were initially detected using a radioimmunoassay which detects immunoprecipitation of alphadendrotoxin-labelled VGKCs from mammalian brain tissue. Subsequent inductive biochemical experiments have demonstrated that some VGKC antibodies are not usually directed against the VGKCs themselves but against one or more of three proteins strongly complexed with the VGKC in mammalian brain: LGI1, CASPR2 and contactin-2 (Irani et al. 2010b).

LGI1 antibodies are more frequently associated with epilepsy and encephalopathy syndromes, while CASPR2 antibodies are more commonly associated with disorders of peripheral nerve hyperexcitability including Morvan's syndrome. This is consistent with the CNS-predominant expression of LGI1, whereas CASPR2 is expressed densely at juxtaparanodes in the CNS and PNS. A highly distinctive seizure semiology described as faciobrachial dystonic seizures (FBDS) precedes the development of frank encephalopathy in a proportion of cases with LGI1 antibodies (Irani et al. 2011). Both LGI1 and CASPR2 antibody-associated encephalopathies respond well to prompt immunotherapy, although residual amnestic deficits are common (Butler et al. 2014) and may occur as a function of time to treatment in LGI1 antibody encephalopathy (Irani et al. 2013).

Functionally, LGI1 antibodies specifically block the binding of LGI1 to ADAM22/ADAM23 with a corresponding decrease in synaptic AMPAR density (Ohkawa et al. 2013). However, given the clear phenotypic differences between LGI1 antibody encephalitis and AMPAR antibody encephalitis (see below), it is likely that LGI1 antibodies find clinical expression through mechanisms additional to a reduction of synaptic AMPAR numbers or function. In this regard, there is evidence from a single study that LGI1 antibodies may also act via direct interference with the VGKCs, potentiating hippocampal mossy fibre to CA3 pyramidal cell transmission (Lalic et al. 2011). This is also supported by the frequent detection of LGI1 antibodies using the VGKC complex radioimmunoassay.

Intriguingly, mutations in the LGI1 gene in humans are associated with lateral temporal lobe epilepsy syndromes with prominent auditory and sometimes visual and even psychic auras (Striano et al. 2011). The mutations are not however associated with increased rates of primary psychiatric illness. Mutations in the gene encoding CASPR2, CNTNAP2, are associated with schizophrenia, epilepsy and autism (Alarcon et al. 2008; Friedman et al. 2008).

\section{AMPA receptor antibodies}

Antibodies to the GluR1 and GluR2 AMPAR subunits have been associated with limbic encephalitis characterised by short-term memory deficits, emotional and behavioural changes and seizures. Initially described in ten patients from a series of 109 cases of limbic encephalitis, the majority of cases were older women and seven had tumours (of the lung, breast or thymus). Nine patients responded to immunotherapy or oncological therapy. However, neurological relapses without tumour recurrence were frequent (Lai et al. 2009).

More recently, two studies retrospectively tested for AMPAR antibodies in samples from patients with more varied clinical presentations (Hoftberger et al. 2015; Dogan Onugoren et al. 2014). One included 4,819 samples from patients with a wide range of neuropsychiatric presentations. Three were positive for GluR2 AMPAR antibodies, with one having an ovarian tumour. All presented with memory deficits, and two had psychiatric symptoms, including anxiety and mood symptoms (Dogan Onugoren et al. 2014). The other study contained 10,573 patients presenting with suspected encephalitis or paraneoplastic syndromes and found 22 patients positive for AMPAR antibodies. Six had psychotic symptoms as part of their presentation. One of these patients presented with a week of an isolated psychotic illness, before developing neuroleptic malignant syndrome in response to antipsychotic medication. Most patients had a tumour and a good or partial response to immunotherapy or surgery (Hoftberger et al. 2015).

Case studies further highlight the potential for presentations with almost exclusively psychiatric symptoms. Two describe patients presenting with acute behavioural changes 
(agitation, confusion and aggression). One had an associated dysphasia, and the other had a past history of thymoma. Both showed a poor response to neuroleptics but a good response to corticosteroids (Graus et al. 2010). The third describes an older woman presenting with headache, confusion, hallucinations and paranoia. Her symptoms responded to IVIg therapy but relapsed (Elamin et al. 2015). These case studies raise the possibility of a predominantly psychiatric presentation with limited neurological associations, potentially amenable to immunomodulation (Graus et al. 2010). Other case studies describe psychiatric symptoms but as part of a more varied clinical presentation (Bataller et al. 2010; Wei et al. 2013).

\section{Potential mechanisms of AMPAR antibodies}

AMPAR antibodies reversibly reduce the total surface amount and synaptic localization of GLuR1 and GLuR2 containing AMPARs by internalisation and degradation of AMPAR clusters (Lai et al. 2009; Peng et al. 2015), with an accompanying reduction in AMPAR-medicated currents (Gleichman et al. 2014; Peng et al. 2015). Together, these changes appear to result in a compensatory decrease of inhibitory synaptic transmission and increase in intrinsic excitability of neurons.

AMPARs are ionotropic glutamate receptors involved in both fast glutamatergic neurotransmission and activation of NMDARs (Malinow and Malenka 2002). By the nature of their interaction with NMDARs, it is possible that changes in the activity of these receptors could induce psychotic symptoms. They are important in synaptic plasticity, learning and memory (Malinow and Malenka 2002; Kessels and Malinow 2009; Keifer and Zheng 2010). Post-mortem studies have found alterations in the expression and binding sites of AMPAR in schizophrenia (Rubio et al. 2012; Meador-Woodruff and Healy 2000) and mood disorders (Freudenberg et al. 2015; Alt et al. 2006; Gibbons et al. 2012). Mice lacking the AMPA GLuR1 receptor display schizophrenia-related behaviours (Wiedholz et al. 2008) and depressive-related behaviours (Chourbaji et al. 2008).

AMPAR potentiating drugs have moderate effect on cognitive symptoms in schizophrenia when co-administered with antipsychotics, but this is the subject of an ongoing research (Goff et al. 2001; Menniti et al. 2013). There is also evidence for an antidepressant effect in animal studies, and clinical trials are in progress (Freudenberg et al. 2015; Alt et al. 2006; Li et al. 2001).

\section{GABA receptor antibodies}

Antibodies to the $\mathrm{GABA}_{\mathrm{B}}$ receptor have been described in limbic encephalitis with seizures and associate with an underlying lung or neuroendocrine tumour in approximately half of patients (Hoftberger et al. 2013). The psychiatric features described as part of the limbic encephalitis (memory loss, confusion, personality change; psychosis occurring in about a third (Lancaster et al. 2010)) do not differentiate $\mathrm{GABA}_{\mathrm{B}} \mathrm{R}$ encephalitis from other NSAb-associated limbic encephalitides.

$\mathrm{GABA}_{\mathrm{A}} \mathrm{R}$ antibodies targeting isoforms containing $\alpha_{1}$ or $\beta_{3}$ subunits were described in a series of 18 patients, of whom six had high titre antibodies which were also detectable in CSF and presented with severe encephalitis and refractory seizures. The other subjects, with lower titre antibodies detectable in serum only, had a more varied clinical presentation and often had other serum NSAbs (Petit-Pedrol et al. 2014). Pettingill and colleagues retrospectively identified $\mathrm{GABA}_{\mathrm{A}} \mathrm{R}$ antibodies specific for the $\alpha_{1}$ and $\gamma_{2}$ subunits in the sera of 40 of 2,046 patients with varied clinical features whose sera were negative for other NSAbs (Pettingill et al. 2015). Surprisingly, around half were IgM antibodies but all bound to live neurons. This approach has resulted in more varied clinical associations: psychiatric features were present in 5/15 for whom clinical data were available - these included patients with established psychiatric diagnoses of schizophrenia, obsessive-compulsive disorder and 'catatonia of unknown origin'. This last patient was a 17-year-old male who presented with anxiety, obsessionality and psychosis symptoms before developing catatonic motor symptoms which improved with plasma exchange on two separate occasions.

\section{Potential mechanisms of GABAR antibody effects}

GABAR hypofunction is a plausible mechanism for the generation of psychiatric symptoms in these patients. Polymorphisms in genes encoding GABARs have been associated with multiple psychiatric presentations, including autism, anxiety disorders and psychotic disorders. Reduced $\mathrm{GABA}_{\mathrm{A}} \mathrm{R}$ availability is associated with psychotic disorders (Frankle et al. 2015) and clinical risk for such disorders (Kang et al. 2014).

\section{Dopamine receptor antibodies}

Reactivity to D2R was described using ELISA and western blot with antibodies purified from individuals with basal ganglia disorders associated with streptococcal infection, including Sydenham's chorea and paediatric autoimmune neuropsychiatric disorders associated with streptococcal infections (PANDAS), and as such the psychiatric associations encompassed anxiety, obsessions, compulsions and tics (Brimberg et al. 2012). In contrast to most of the NSAbs described here, these antibodies appeared to potentiate rather than antagonise their target receptor-based signalling (Cox et al. 2013; Brimberg et al. 2012). This is in keeping with the considerable evidence for striatal hyperdopaminergia in tic disorders and obsessive-compulsive disorder (OCD) 
(Denys et al. 2013). Increased levels of dopamine D1 receptor antibodies have since been reported in OCD and Tourette syndrome (Cox et al. 2015), but as these were detected with methods that offer less natively conformational epitopes than CBAs their pathogenicity is unclear.

Studies using CBAs confirmed reactivity with cell surface D2Rs (providing stronger evidence of pathogenicity) in Sydenham's chorea but not in PANDAS. These NSAbs were also found in Tourette syndrome and paediatric basal ganglia encephalitis with prominent psychiatric symptoms (also termed paediatric dyskinetic encephalitis lethargica) and first-onset paediatric psychosis (Pathmanandavel et al. 2015; Dale et al. 2012), expanding the psychiatric phenotype to include psychosis. Whether these D2R antibodies stimulate the D2R has not yet been demonstrated, but this would be consistent with the now considerable evidence for dopaminergic overactivity in psychosis (Howes et al. 2012). A large study of adults with schizophrenia experiencing an acute psychotic episode however failed to find D2R antibody positivity in this group (Muller et al. 2014), although notably the CBA methodology differed considerably from the previous study.

\section{Other antigen targets}

Glycine receptor and voltage-gated calcium channel (VGCC) antibodies have been consistently associated with characteristic neurological symptoms but are rarely associated with psychiatric symptoms. This is somewhat surprising in the case of VGCC antibodies given the compelling evidence for the role of calcium ion channel gene defects in multiple psychiatric disorders (Cross-Disorder Group of the Psychiatric Genomics, C 2013). The neuroanatomical specificities of the NSAbs or their cognate antigens may be relevant here, with glycine receptor antibodies predominantly affecting brainstem structures and the described CNS specificities of VGCC antibodies to date appearing to favour the cerebellum (Burk et al. 2010; Fukuda et al. 2003).

To date, fewer than 30 patients have been described with an encephalopathy syndrome associated antibodies to DPPX, a regulatory subunit of A-type (rapidly inactivating) potassium channels (Boronat et al. 2013; Tobin et al. 2014). Although initially described in connection with prominent gastrointestinal symptoms, presumably due to the high levels of DPPX in the myenteric plexus, the disorder can have CNS-only manifestations. From a neuropsychiatric viewpoint, in the largest series described to date, $80 \%$ had amnesia, $40 \%$ delirium and $20 \%$ had each of psychosis and depression (Tobin et al. 2014).

Four patients have been described with limbic encephalitis and antibodies to mGluR5. Psychiatric symptoms including psychosis and affective and personality changes were prominent; three had Hodgkin lymphoma (Lancaster et al. 2011;
Pruss et al. 2014; Mat et al. 2013). The effect of the NSAbs on mGluR5, which is thought to regulate NMDAR-dependent signalling, is unknown. Notably, dysfunction of mGluR5 is implicated in the pathogenesis of glutamate dysfunction in psychiatric disorders including schizophrenia (Matosin et al. 2015). Compounds that act on the mGLuR are being developed for the treatment of schizophrenia (Patil et al. 2007), but it is currently unclear if they are effective.

\section{Non-receptor-based effects}

While this review has emphasised the theoretical utility of viewing NSAb function from a pharmacological perspective, it is important to note that NSAbs have other effects consistent with their role as immune effector molecules. In LGI1 antibody-mediated encephalitis but not in NMDAR antibody encephalitis, for example, there is consistent evidence of complement deposition and associated cell death in patient brain tissue (Bien et al. 2012).

Pathological studies of NMDAR antibody encephalitis have demonstrated the presence of activated microglia (Dalmau et al. 2008). Consistent with this, microglial activation in a man with NMDAR antibody encephalitis has been demonstrated in vivo using a TSPO-specific PET ligand; the degree of microglial activation was found to correlate with clinical severity and antibody titre (Jensen et al. 2015).

Surprisingly, little work has focussed on the role of inflammatory mediators such as cytokines and chemokines in NSAb-associated CNS disease. One study found evidence of involvement of the Th-17 pathway (Ulusoy et al. 2012), but this requires replication and further work to elucidate potential differences in the inflammatory milieu associated with different NSAbs. Given the increasing recognition of the role of inflammation in primary psychiatric disease, studies of this kind may offer further insights of the pathogenesis of antibody-mediated psychiatric symptoms across diagnoses.

The importance of the inflammatory effects of NSAbs in human disease is unclear and is likely to vary according to the antigen target, immunoglobulin subtype (e.g. IgG4 antibodies are thought to act mainly through effects on receptor function (Huijbers et al. 2015)) and disease stage (for example, inflammatory effects may contribute to the residual symptomatology seen in many post-encephalitic patients, as is likely the case in hippocampal atrophy following LGI1-antibody encephalopathy (Malter et al. 2014).

\section{Evidence for NSAbs in primary psychiatric disease}

This review has detailed how NSAbs can cause psychiatric symptoms as part of a wider constellation of neurological symptoms in autoimmune encephalopathies. There is also 
now an understandable vogue to similarly study the neuropsychiatric features of neurological disorders such as epilepsy or dementia, in which NSAbs have been variably linked with the presence of psychiatric symptoms, in particular psychosis (Doss et al. 2014; Busse et al. 2014; Ekizoglu et al. 2014). One of the most controversial areas of psychiatric research today concerns the further question of whether NSAbs have a causal role in psychiatric disorders such as schizophrenia, affective disorders or autistic spectrum disorders.

\section{Controversies and limitations of current evidence}

Despite a considerable research effort, there has been relatively disappointing progress in the identification of novel biological treatments for psychiatric disorders. The possibility of NSAb-mediated psychiatric disease has been met with great enthusiasm probably because it raises the prospect of an entirely new class of therapy for at least a subset of these highly disabling illnesses.

There are presently a number of case studies and series, albeit uncontrolled, demonstrating immunotherapyresponsive psychiatric presentations associated with NSAbs (Table 1). The main controversies remaining are whether serum antibodies alone are sufficient to diagnose an antibodymediated CNS disease and whether these cases are a rarity or whether they might account for a significant proportion of individuals with a given psychiatric diagnosis. Evidence for either possibility is inconsistent and the literature has been beset with debate around the most appropriate methodologies for establishing the presence of causally relevant antibodies.

Most research has focussed on schizophrenia and psychosis, probably because of the frequency with which psychosis features in autoimmune encephalopathies but also because of (a) the theoretically appealing links between neurotransmitter receptors as NSAb targets and the suggested role of these neurotransmitters (e.g. NMDAR, AMPAR, D2R) in the pathogenesis of psychotic disorders, (b) epidemiological evidence highlighting a strikingly increased risk of psychosis in people with autoimmune disorders and vice versa (Benros et al. 2011, 2014) and (c) powerful genome-wide evidence of the centrality of immune-related genes in psychosis (Schizophrenia Working Group of the Psychiatric Genomics, C 2014).

Taking NMDAR antibodies in psychotic disorders as the most studied example, some studies using live, nonpermeabilised CBAs have demonstrated increased rates of NMDAR antibodies in psychotic disorders (Pathmanandavel et al. 2015; Zandi et al. 2011). Studies employing fixed and permeabilised CBAs however have broadly found similar prevalences of NMDAR antibodies in patients and in controls (Dahm et al. 2014; Hammer et al. 2014), while studies using multiple assays have failed to find any NMDAR antibodies in psychotic patients (Masdeu et al. 2012). Notably, as well as the inter-assay variability, patients in each of these studies differed markedly in terms of chronicity and acuity of illness (see (Pollak et al. 2014)).

There are a number of areas of controversy regarding testing for NSAbs, particularly in populations with 'atypical' presentations - that is, whose symptoms differ from the canonical encephalopathy syndromes described above. (1) The necessity of testing CSF as opposed to serum alone is disputed. Intrathecal antibody synthesis appears to be common for some NSAbs but not others (e.g. common in NMDAR antibody encephalitis but not LGI1 antibody encephalitis (Malter et al. 2013)) - but whether antibodies are detectable in CSF may depend on disease stage and the specificities of the assay used such as the dilutions at which serum and CSF are tested (see Irani et al. for further detail (Irani et al. 2014)). (2) The decision to use fixed as opposed to live CBAs may impact the outcome of prevalence studies since fixation of cells modifies the antigen and permeabilises the cell membrane. The latter may expose intracellular antigens and therefore potentially detect causally irrelevant antibodies. (3) The association between psychiatric disorders and NSAbs may depend on the seropositivity threshold employed in the CBA, with one metaanalysis indicating higher odds of NMDAR antibody seropositivity in psychotic and affective disorders at lower titres (Pearlman and Najjar 2014). Most CBAs ascertain titre by performing serial dilutions and ascertaining the lowest dilution at which immunofluorescence is detected. More finely grained quantitative CBA results are possible using fluorescence-activated cell sorting (Amatoury et al. 2013), but so far, this is limited to a small number of laboratories and the sensitivity of the method has in one study been shown to be inferior to microscopy (Ramberger et al. 2015). (4) Since NMDAR antibody encephalitis is associated with IgG antibodies, it had been assumed that only these antibodies had functional effects and hence could cause disease. However, as mentioned in the section on NMDAR antibodies, there is now increasing evidence that antibodies of $\operatorname{IgA}$ and IgM subclasses may have a pathogenic role in psychiatric and neurodegenerative disorders (Pruss et al. 2012a; Doss et al. 2014; Choe et al. 2013; Hammer et al. 2014). (5) Finally, the necessity of confirming a CBA result with other techniques to demonstrate immunoreactivity, such as immunohistochemistry or assessment of antibody binding to cultured neurons, is also debated (Zandi et al. 2015; Kayser 2015).

\section{Future directions}

It is clear at this stage that studies purporting to show an increased prevalence of a given NSAb in a particular psychiatric patient group cannot in isolation establish that these antibodies have any pathogenic role. Although the recognised frequencies of these antibodies in a variety of disease and healthy populations (Dahm et al. 2014) suggest that thorough epidemiology should be revisited with detailed clinical 
correlations. One potentially powerful argument for the causal relevance of NSAbs in individuals with a psychiatric diagnosis comes from case reports and series demonstrating psychiatric improvement following immunotherapy in patients with NSAbs and a primary psychiatric diagnosis (Zandi et al. 2011, 2014) - although this could relate to an antibody-independent immunological process for which the antibody is a noncausative biomarker. Randomised controlled trials of immunotherapy in these patient groups are necessary to establish efficacy before standard psychiatric treatment is substantially changed, however.

Another argument for pathogenicity of NSAbs in psychiatric groups comes from increasing evidence of in vivo and in vitro functional effects of antibodies from patients with a primary psychiatric disorder (Choe et al. 2013; Hammer et al. 2014). That is, if the effects on receptor number, function and cell signalling, or indeed animal behaviour, resemble those seen with antibodies from patients with encephalitis (Table 2), then the case for pathogenicity of these NSAbs would appear at least equal to that in cases of encephalitis. However, if the antibodies are derived from the serum, it may be that the CNS is never accessed by these IgG species.

An alternative question concerns whether, when found in individuals with psychiatric disorders, NSAbs are a secondary phenomenon, emerging as part of an immune response to whichever pathogenetic process is driving the disease process. Importantly, this does not exclude the possibility that NSAbs, even if secondary, can influence clinical phenotype and/or disease course. One way to distinguish this possibility from a more straightforward causal role would be if NSAbs were not detected in serum samples from individuals at high risk for psychiatric illness (e.g. the 'at-risk mental state' for psychotic disorders) but became detectable after the onset of clinical disease. Alternatively, NSAbs may have prognostic significance in psychiatric disorders, akin to the prognostic role of other autoantibodies in many disorders throughout medicine.

Much work remains to be done to elucidate the conditions required for NSAbs to be produced and to cause CNS dysfunction, with potential relevance for psychiatry. Some authors have highlighted the importance of blood-brain barrier (BBB) dysfunction in determining whether peripheral antibodies can reach the CNS and exert pathogenic functional effects (Hammer et al. 2014; Huerta et al. 2006; Levin et al. 2010). With increasing recognition that the majority of NSAb seropositivity is not associated primarily with malignancy, attention has also turned to infection as a potential antecedent of pathogenic NSAb formation; possible mechanisms include nonspecific adaptive immune response to neuronal damage and molecular mimicry (Bogdanos et al. 2013). Particular links between the formation of glutamate receptor antibodies and influenza (Hammer et al. 2014), HSV-1 (Pruss et al. 2012b; Armangue et al. 2014), EBV (Xu et al. 2011) and other viral (Koustova et al. 2001) infections have been demonstrated. Interestingly, serological evidence of viral or other infections has also been linked with risk for psychosis (Wang et al. 2011; Amminger et al. 2007; Yolken and Torrey 2008) or with particular phenotypes within psychosis populations including cognitive impairment (Shirts et al. 2008) and neuroimaging abnormalities (Schretlen et al. 2010; Prasad et al. 2011); whether NSAbs might mediate this relationship in a subset of cases has not been explored.

\section{Therapeutic considerations}

NSAbs are immune effector molecules which target specific CNS receptor targets or other antigenic targets which directly impact upon receptor function. Therapeutically, two broad approaches can therefore be considered: immunological and receptor-based therapies. Precedent for this can be found in the treatment of myasthenia gravis, in which most patients have antibodies to cell surface nicotinic acetylcholine receptors. Therapy for the disease is usually a combination of immunotherapy targeting the antibodies and cholinergic therapy aimed at restoring the cholinergic balance at the neuromuscular junction. Similarly, targeted therapies for NSAb-mediated disease may similarly be employed simultaneously on two fronts.

Current immunotherapy for NSAb-mediated CNS disease can be divided into first-line and second-line therapies. Firstline therapies include oral or intravenous steroids for nonspecific immunosuppression, plasma exchange and intravenous immunoglobulins. Second-line therapies include cyclophosphamide, mycophenolate mofetil and B cell-specific depletion including the anti-CD20 monoclonal antibody rituximab. Other immunological therapies currently in use in rheumatology and neurology clinics may yet have application in NSAbmediated disease. Promising compounds are likely to be those specifically targeting B cells and plasma cells and associated antibody production, either directly or indirectly (e.g. tocilizumab, which targets the IL-6 receptor on B cells (Irani and Vincent 2015)). Immunotherapies are associated with a number of potentially serious side effects and should be used with caution in the patients most likely to benefit. Side effects include increased risk of infection (including serious opportunistic infections of the CNS and systemically) with immunosuppressive treatments, fever, headache and anaphylaxis with intravenous immunoglobulins and cardiovascular instability with plasma exchange. Interestingly, steroid-induced psychosis is very rarely reported in the treatment of autoimmune encephalopathies. This may be because psychosis is often a presenting symptom of the illness itself, and hence exacerbations are more likely to go unnoticed or ascribed to illness progression or potentially may be related to differential mechanisms underlying behavioural disturbance in these individuals. 
One example of the second, receptor-based approach has been described in a therapeutic open-label case study by Heresco-Levy and colleagues who gave D-serine to a female with an NMDAR antibody-positive woman with a diagnosis of chronic treatment-refractory schizophrenia. She also had cortical and subcortical white matter MRI hyperintensities and runs of 'extreme delta brush' on EEG (a pattern thought to be pathognomonic of NMDAR antibody-mediated CNS disease). Following treatment with D-serine, which is a NMDAR co-agonist thought to enhance NMDAR function by increasing the frequency of channel opening, the patient's EEG normalised and her psychosis improved (Heresco-Levy et al. 2015).

Another future potential receptor-based approach, arising from the work of Diamond and colleagues on NMDA NR2 antibodies in neuropsychiatric SLE, involves the synthesis and systemic administration of a D-peptide which prevents binding of antibody to its binding site without directly affecting receptor function: in mice, these were well tolerated and blocked the neurotoxic effects of NR2 NMDAR antibodies (Huerta et al. 2006). Approaches using conformational epitopes would be required in autoimmune encephalopathies, as the antibodies recognise non-linear native confirmations of the target proteins. Other strategies aimed at blocking antibodyantigen interaction are in development in neuromyelitis optica and may also have application in NSAb-mediated disorders (Papadopoulos et al. 2014).

\section{Antibodies as therapeutic agents}

Speculatively, and bearing in mind the growth of antibody-based therapeutics in medicine generally, one could foresee how recent work on NSAbs could facilitate the development of functionally active antibodies to specific receptor targets as an emergent therapeutic strategy within neuropsychopharmacology. There is limited evidence that in some circumstances NSAbs could have a protective function: Zerche and colleagues have demonstrated that pre-existent NMDAR antibodies limit lesion size following stroke in individuals with an intact BBB (Zerche et al. 2015). Although the mechanism is not known, it may be that NMDARAb-mediated receptor hypofunction limited glutamate-mediated excitotoxicity in these individuals.

\section{Conclusion}

Increasingly, NSAbs are being reported in diverse clinical populations with a range of psychiatric phenotypes. We have presented convergent evidence that, outside of narrowly defined psychiatric populations at the very least, NSAbs are associated with a number of psychiatric syndromes, including psychosis, tic and mood disorders, and evidence that immunotherapy to treat the NSAbs is effective in treating the psychiatric symptoms. However, several areas of controversy remain, in particular whether the expanding numbers of studies reporting increased prevalence of NSAbs in primary psychiatric populations might require us to reconceptualize the nature of a subset of these disorders. Studies demonstrating whether NSAbs from psychiatric patients have functional effects in vivo and in vitro are urgently required to address this question, as are well-controlled trials of immunological therapies in appropriately selected antibody-positive patients.

NSAbs are potent effector molecules within the CNS that can have profound effects on neuronal receptor function. Their high affinity and remarkable specificities could offer opportunities to study the biology of CNS-active molecules in humans. A combined psychopharmacological and immunological approach to understanding their mechanisms of action is necessary to understand both the neurobiological basis of psychiatric symptoms as well as to develop new treatment strategies that will arise from the inevitably improved understanding of antibody-antigen interaction within the CNS.

Acknowledgments The authors would like to thank Professor Angela Vincent and Dr. Tim Nicholson for their valuable comments and insights.

Funding and disclosures Dr. Pollak was supported by a clinical research training fellowship grant from the Wellcome Trust (no. 105758/Z/ $14 / Z$ ).

Dr. Howes was funded by Medical Research Council-UK (no. MCA656-5QD30), Maudsley Charity (no. 666) and Wellcome Trust (no. 094849/Z/10/Z) grants.

Dr. Howes has received investigator-initiated research funding from and/or participated in advisory/speaker meetings organised by AstraZeneca, Autifony, BMS, Eli Lilly, Jansenn, Lundbeck, Lyden-Delta, Otsuka, Servier, Sunovion and Roche. Neither Dr. Howes nor his family have been employed by or have holdings/a financial stake in any biomedical company.

Dr. Irani is supported by a Wellcome Trust Intermediate Fellowship and the British Medical Association Vera Down Research Grant and is a member of the Oxford Epilepsy Research Group. Dr. Irani is a coapplicant on a patent with Oxford University for VGKC complex antibodies licensed to Euroimmun and has received royalties (licensee ISIS).

Professor McGuire has received consultancy fees from Hoffman la Roche and Sunovion.

The authors acknowledge financial support from the National Institute for Health Research (NIHR) Biomedical Research Centre for Mental Health at South London and Maudsley NHS Foundation Trust and King's College London. The views expressed are those of the authors and not necessarily those of the NHS, the NIHR or the Department of Health.

Open Access This article is distributed under the terms of the Creative Commons Attribution 4.0 International License (http:// creativecommons.org/licenses/by/4.0/), which permits unrestricted use, distribution, and reproduction in any medium, provided you give appropriate credit to the original author(s) and the source, provide a link to the Creative Commons license, and indicate if changes were made. 


\section{References}

Alarcon M et al (2008) Linkage, association, and gene-expression analyses identify CNTNAP2 as an autism-susceptibility gene. Am J Hum Genet 82(1):150-159

Alt A et al (2006) A role for AMPA receptors in mood disorders. Biochem Pharmacol 71(9):1273-1288

Amatoury M et al (2013) High-throughput flow cytometry cell-based assay to detect antibodies to N-methyl-D-aspartate receptor or dopamine-2 receptor in human serum. J Vis Exp 81:e50935

Amminger GP et al (2007) Antibodies to infectious agents in individuals at ultra-high risk for psychosis. Biol Psychiatry 61(10):1215-1217

Armangue T et al (2014) Herpes simplex virus encephalitis is a trigger of brain autoimmunity. Ann Neurol 75(2):317-323

Balint B et al (2014) Progressive encephalomyelitis with rigidity and myoclonus: a new variant with DPPX antibodies. Neurology 82(17):1521-1528

Bataller L et al (2010) Reversible paraneoplastic limbic encephalitis associated with antibodies to the AMPA receptor. Neurology 74(3):265-267

Beck K et al (2015) Prevalence of serum N-methyl-D-aspartate receptor autoantibodies in refractory psychosis. Br J Psychiatry 206(2):164-165

Belforte JE et al (2010) Postnatal NMDA receptor ablation in corticolimbic interneurons confers schizophrenia-like phenotypes. Nat Neurosci 13(1):76-83

Benros ME et al (2011) Autoimmune diseases and severe infections as risk factors for schizophrenia: a 30-year population-based register study. Am J Psychiatry 168(12):1303-1310

Benros ME et al (2014) A nationwide study on the risk of autoimmune diseases in individuals with a personal or a family history of schizophrenia and related psychosis. Am J Psychiatry 171(2):218-226

Bergink V et al (2015) Autoimmune encephalitis in postpartum psychosis. Am J Psychiatry: p. appiajp201514101332.

Bien CG et al (2012) Immunopathology of autoantibody-associated encephalitides: clues for pathogenesis. Brain 135(Pt 5):1622-1638

Bogdanos DP et al (2013) Infectome: a platform to trace infectious triggers of autoimmunity. Autoimmun Rev 12(7):726-740

Boronat A et al (2013) Encephalitis and antibodies to dipeptidylpeptidase-like protein-6, a subunit of Kv4.2 potassium channels. Ann Neurol 73(1):120-128

Brimberg L et al (2012) Behavioral, pharmacological, and immunological abnormalities after streptococcal exposure: a novel rat model of Sydenham chorea and related neuropsychiatric disorders. Neuropsychopharmacology 37(9):2076-2087

Buckley $\mathrm{C}$ et al (2001) Potassium channel antibodies in two patients with reversible limbic encephalitis. Ann Neurol 50(1):73-78

Burk K et al (2010) Antineuronal antibodies in sporadic late-onset cerebellar ataxia. J Neurol 257(1):59-62

Busse $\mathrm{S}$ et al (2014) N-methyl-d-aspartate glutamate receptor (NMDA-R) antibodies in mild cognitive impairment and dementias. Neurosci Res 85:58-64

Butler CR et al (2014) Persistent anterograde amnesia following limbic encephalitis associated with antibodies to the voltage-gated potassium channel complex. J Neurol Neurosurg Psychiatry 85(4):387-391

Choe CU et al (2013) A clinical and neurobiological case of IgM NMDA receptor antibody associated encephalitis mimicking bipolar disorder. Psychiatry Res 208(2):194-196

Chourbaji S et al (2008) AMPA receptor subunit 1 (GluR-A) knockout mice model the glutamate hypothesis of depression. FASEB J 22(9): 3129-3134

Cornelius JR et al (2011) Sleep manifestations of voltage-gated potassium channel complex autoimmunity. Arch Neurol 68(6):733-738

Cox CJ et al (2013) Brain human monoclonal autoantibody from sydenham chorea targets dopaminergic neurons in transgenic mice and signals dopamine D2 receptor: implications in human disease. J Immunol 191(11):5524-5541
Cox CJ et al (2015) Antineuronal antibodies in a heterogeneous group of youth and young adults with tics and obsessive-compulsive disorder. J Child Adolesc Psychopharmacol 25(1):76-85

Creten C et al (2011) Late onset autism and anti-NMDA-receptor encephalitis. Lancet 378(9785):98

Cross-Disorder Group of the Psychiatric Genomics, C (2013) Identification of risk loci with shared effects on five major psychiatric disorders: a genome-wide analysis. Lancet 381(9875):1371-1379

Dahm L et al (2014) Seroprevalence of autoantibodies against brain antigens in health and disease. Ann Neurol 76(1):82-94

Dale RC et al (2012) Antibodies to surface dopamine-2 receptor in autoimmune movement and psychiatric disorders. Brain 135(Pt 11): 3453-3468

Dalmau J et al (2007) Paraneoplastic anti-N-methyl-D-aspartate receptor encephalitis associated with ovarian teratoma. Ann Neurol 61(1):25-36

Dalmau J et al (2008) Anti-NMDA-receptor encephalitis: case series and analysis of the effects of antibodies. Lancet Neurol 7(12):10911098

de Witte LD et al (2015) Absence of N-Methyl-D-Aspartate Receptor IgG Autoantibodies in Schizophrenia: The Importance of CrossValidation Studies. JAMA Psychiatry 72(7):731-733

Deakin J, Lennox BR, Zandi MS (2014) Antibodies to the N-methyl-Daspartate receptor and other synaptic proteins in psychosis. Biol Psychiatry 75(4):284-291

Denys D et al (2013) Dopaminergic activity in Tourette syndrome and obsessive-compulsive disorder. Eur Neuropsychopharmacol 23(11): 1423-1431

Dogan Onugoren $\mathrm{M}$ et al (2014) Limbic encephalitis due to GABAB and AMPA receptor antibodies: a case series. J Neurol Neurosurg Psychiatry

Doss S et al (2014) High prevalence of NMDA receptor IgA/IgM antibodies in different dementia types. Ann Clin Transl Neurol 1(10): $822-832$

Ekizoglu E et al (2014) Investigation of neuronal autoantibodies in two different focal epilepsy syndromes. Epilepsia 55(3):414-422

Elamin M et al (2015) Posterior cortical and white matter changes on MRI in anti-AMPA receptor antibody encephalitis. Neurol Neuroimmunol Neuroinflamm 2(4):e118

Finke C et al (2012) Cognitive deficits following anti-NMDA receptor encephalitis. J Neurol Neurosurg Psychiatry 83(2):195-198

Finke C et al (2015) Structural hippocampal damage following anti-Nmethyl-D-aspartate receptor encephalitis. Biol Psychiatry

Frankle WG et al (2015) In vivo measurement of GABA transmission in healthy subjects and schizophrenia patients. Am J Psychiatry: p. appiajp201514081031.

Freudenberg F, Celikel T, Reif A (2015) The role of alpha-amino-3-hydroxy-5-methyl-4-isoxazolepropionic acid (AMPA) receptors in depression: central mediators of pathophysiology and antidepressant activity? Neurosci Biobehav Rev 52:193-206

Friedman JI et al (2008) CNTNAP2 gene dosage variation is associated with schizophrenia and epilepsy. Mol Psychiatry 13(3):261-266

Fukuda $\mathrm{T}$ et al (2003) Reduction of P/Q-type calcium channels in the postmortem cerebellum of paraneoplastic cerebellar degeneration with Lambert-Eaton myasthenic syndrome. Ann Neurol 53(1):2128

Gibbons AS et al (2012) AMPA receptor expression is increased postmortem samples of the anterior cingulate from subjects with major depressive disorder. J Affect Disord 136(3):1232-1237

Gleichman AJ et al (2012) Anti-NMDA receptor encephalitis antibody binding is dependent on amino acid identity of a small region within the GluN1 amino terminal domain. J Neurosci 32(32):11082-11094

Gleichman AJ et al (2014) Antigenic and mechanistic characterization of anti-AMPA receptor encephalitis. Ann Clin Transl Neurol 1(3):180-189 
Goff DC et al (2001) A placebo-controlled pilot study of the ampakine CX516 added to clozapine in schizophrenia. J Clin Psychopharmacol 21(5):484-487

Graus F, Dalmau J (2012) Paraneoplastic neurological syndromes. Curr Opin Neurol 25(6):795-801

Graus F et al (2010) The expanding clinical profile of anti-AMPA receptor encephalitis. Neurology 74(10):857-859

Hall J et al (2015) Genetic risk for schizophrenia: convergence on synaptic pathways involved in plasticity. Biol Psychiatry 77(1):52-58

Hammer $\mathrm{C}$ et al (2014) Neuropsychiatric disease relevance of circulating anti-NMDA receptor autoantibodies depends on blood-brain barrier integrity. Mol Psychiatry 19(10):1143-1149

Heresco-Levy U et al (2015) Clinical and electrophysiological effects of D-serine in a schizophrenia patient positive for anti-N-methyl-Daspartate receptor antibodies. Biol Psychiatry 77(6):e27-e29

Hoftberger R et al (2013) Encephalitis and GABAB receptor antibodies: novel findings in a new case series of 20 patients. Neurology 81(17): $1500-1506$

Hoftberger R et al (2015) Encephalitis and AMPA receptor antibodies: novel findings in a case series of 22 patients. Neurology 84(24): 2403-2412

Howes OD et al (2012) The nature of dopamine dysfunction in schizophrenia and what this means for treatment. Arch Gen Psychiatry 69(8):776-786

Howes O, McCutcheon R, Stone J (2015) Glutamate and dopamine in schizophrenia: an update for the 21st century. J Psychopharmacol 29(2):97-115

Huerta PT et al (2006) Immunity and behavior: antibodies alter emotion. Proc Natl Acad Sci U S A 103(3):678-683

Hughes EG et al (2010) Cellular and synaptic mechanisms of antiNMDA receptor encephalitis. J Neurosci 30(17):5866-5875

Huijbers MG et al (2015) The expanding field of IgG4-mediated neurological autoimmune disorders. Eur J Neurol 22(8):1151-1161

Irani SR, Vincent A (2015) Targeting the Interleukin 6 Receptor to Treat Neuromyelitis Optica. JAMA Neurol 72(7):747-748

Irani SR et al (2010a) N-methyl-D-aspartate antibody encephalitis: temporal progression of clinical and paraclinical observations in a predominantly non-paraneoplastic disorder of both sexes. Brain 133(Pt 6): $1655-1667$

Irani SR et al (2010b) Antibodies to Kv1 potassium channel-complex proteins leucine-rich, glioma inactivated 1 protein and contactinassociated protein-2 in limbic encephalitis, Morvan's syndrome and acquired neuromyotonia. Brain 133(9):2734-2748

Irani SR et al (2011) Faciobrachial dystonic seizures precede Lgil antibody limbic encephalitis. Ann Neurol 69(5):892-900

Irani SR et al (2012) Morvan syndrome: clinical and serological observations in 29 cases. Ann Neurol 72(2):241-255

Irani SR et al (2013) Faciobrachial dystonic seizures: the influence of immunotherapy on seizure control and prevention of cognitive impairment in a broadening phenotype. Brain 136(Pt 10):3151-3162

Irani SR et al (2014) Cell-surface central nervous system autoantibodies: clinical relevance and emerging paradigms. Ann Neurol 76(2):168184

Javitt DC (2007) Glutamate and schizophrenia: phencyclidine, N-methylD-aspartate receptors, and dopamine-glutamate interactions. Int Rev Neurobiol 78:69-108

Javitt DC, Zukin SR (1991) Recent advances in the phencyclidine model of schizophrenia. Am J Psychiatry 148(10):1301-1308

Jeffery OJ et al (2013) GABAB receptor autoantibody frequency in service serologic evaluation. Neurology 81(10):882-887

Jensen P et al (2015) Anti-NMDAR encephalitis: demonstration of neuroinflammation and the effect of immunotherapy. Neurology 84(8):859

Kang JI et al (2014) Reduced binding potential of GABA-A/benzodiazepine receptors in individuals at ultra-high risk for psychosis: an
[18F]-fluoroflumazenil positron emission tomography study. Schizophr Bull 40(3):548-557

Kayser MS (2015) Fact or fiction? Examining a role for N-methyl-Daspartate receptor autoantibodies in psychiatric illness. Biol Psychiatry 77(6):506-507

Kayser MS et al (2013) Frequency and characteristics of isolated psychiatric episodes in anti-N-methyl-d-aspartate receptor encephalitis. JAMA neurol 70(9):1133-1139

Keifer J, Zheng Z (2010) AMPA receptor trafficking and learning. Eur J Neurosci 32(2):269-277

Kessels HW, Malinow R (2009) Synaptic AMPA receptor plasticity and behavior. Neuron 61(3):340-350

Kirov G et al (2012) De novo CNV analysis implicates specific abnormalities of postsynaptic signalling complexes in the pathogenesis of schizophrenia. Mol Psychiatry 17(2):142-153

Klang A et al (2014) IgG and complement deposition and neuronal loss in cats and humans with epilepsy and voltage-gated potassium channel complex antibodies. J Neuropathol Exp Neurol 73(5):403-413

Koustova $\mathrm{E}$ et al (2001) LP-BM5 virus-infected mice produce activating autoantibodies to the AMPA receptor. J Clin Invest 107(6):737-744

Lai M et al (2009) AMPA receptor antibodies in limbic encephalitis alter synaptic receptor location. Ann Neurol 65(4):424-434

Lalic T et al (2011) Human limbic encephalitis serum enhances hippocampal mossy fiber-CA3 pyramidal cell synaptic transmission. Epilepsia 52(1):121-131

Lancaster E et al (2010) Antibodies to the GABA(B) receptor in limbic encephalitis with seizures: case series and characterisation of the antigen. Lancet Neurol 9(1):67-76

Lancaster E et al (2011) Antibodies to metabotropic glutamate receptor 5 in the Ophelia syndrome. Neurology 77(18):1698-1701

Lauvsnes MB, Omdal R (2012) Systemic lupus erythematosus, the brain, and anti-NR2 antibodies. J Neurol 259(4):622-629

Lauvsnes MB et al (2014) Association of hippocampal atrophy with cerebrospinal fluid antibodies against the NR2 subtype of the Nmethyl-D-aspartate receptor in patients with systemic lupus erythematosus and patients with primary Sjogren's syndrome. Arthritis Rheumatol 66(12):3387-3394

Levin EC et al (2010) Brain-reactive autoantibodies are nearly ubiquitous in human sera and may be linked to pathology in the context of blood-brain barrier breakdown. Brain Res 1345:221-232

Li X et al (2001) Antidepressant-like actions of an AMPA receptor potentiator (LY392098). Neuropharmacology 40(8):1028-1033

Liguori R et al (2001) Morvan's syndrome: peripheral and central nervous system and cardiac involvement with antibodies to voltagegated potassium channels. Brain 124(Pt 12):2417-2426

Liu J, Moghaddam B (1995) Regulation of glutamate efflux by excitatory amino acid receptors: evidence for tonic inhibitory and phasic excitatory regulation. J Pharmacol Exp Ther 274(3):1209-1215

Malinow R, Malenka RC (2002) AMPA receptor trafficking and synaptic plasticity. Annu Rev Neurosci 25:103-126

Malter MP, Elger CE, Surges R (2013) Diagnostic value of CSF findings in antibody-associated limbic and anti-NMDAR-encephalitis. Seizure 22(2):136-140

Malter MP et al (2014) Outcome of limbic encephalitis with VGKCcomplex antibodies: relation to antigenic specificity. J Neurol 261(9):1695-1705

Manto M et al (2010) In vivo effects of antibodies from patients with antiNMDA receptor encephalitis: further evidence of synaptic glutamatergic dysfunction. Orphanet J Rare Dis 5:31

Martinez-Hernandez E et al (2011) Analysis of complement and plasma cells in the brain of patients with anti-NMDAR encephalitis. Neurology 77(6):589-593

Masdeu JC et al (2012) Serum IgG antibodies against the NR1 subunit of the NMDA receptor not detected in schizophrenia. Am J Psychiatry 169(10):1120-1121 
Masopust J et al (2015) Anti-NMDA receptor antibodies in patients with a first episode of schizophrenia. Neuropsychiatr Dis Treat 11:619 623

Mat A et al (2013) Ophelia syndrome with metabotropic glutamate receptor 5 antibodies in CSF. Neurology 80(14):1349-1350

Matosin N et al (2015) Alterations of mGluR5 and its endogenous regulators Norbin, Tamalin and Preso1 in schizophrenia: towards a model of mGluR5 dysregulation. Acta Neuropathol 130(1):119-129

Meador-Woodruff JH, Healy DJ (2000) Glutamate receptor expression in schizophrenic brain. Brain Res Brain Res Rev 31(2-3):288-294

Mechelhoff D et al (2015) Anti-NMDA receptor encephalitis presenting as atypical anorexia nervosa: an adolescent case report. Eur Child Adolesc Psychiatry

Menniti FS et al (2013) Allosteric modulators for the treatment of schizophrenia: targeting glutamatergic networks. Curr Top Med Chem 13(1):26-54

Mikasova L et al (2012) Disrupted surface cross-talk between NMDA and Ephrin-B2 receptors in anti-NMDA encephalitis. Brain 135(Pt 5):1606-1621

Moscato EH et al (2014) Acute mechanisms underlying antibody effects in anti-N-methyl-D-aspartate receptor encephalitis. Ann Neurol 76(1):108-119

Muller UJ et al (2014) Absence of dopamine receptor serum autoantibodies in schizophrenia patients with an acute disease episode. Schizophr Res 158(1-3):272-274

Niehusmann P et al (2009) Diagnostic value of N-methyl-D-aspartate receptor antibodies in women with new-onset epilepsy. Arch Neurol 66(4):458-464

Ohkawa T et al (2013) Autoantibodies to epilepsy-related LGI1 in limbic encephalitis neutralize LGI1-ADAM22 interaction and reduce synaptic AMPA receptors. J Neurosci 33(46):18161-18174

Olsen AL et al (2015) Caspr2 autoantibodies target multiple epitopes. Neurol Neuroimmunol Neuroinflamm 2(4):e127

Papadopoulos MC, Bennett JL, Verkman AS (2014) Treatment of neuromyelitis optica: state-of-the-art and emerging therapies. Nat Rev Neurol 10(9):493-506

Parthasarathi UD et al (2006) Psychiatric presentation of voltage-gated potassium channel antibody-associated encephalopathy. Case report Br J Psychiatry 189:182-183

Paterson RW et al (2014) Clinical relevance of positive voltage-gated potassium channel (VGKC)-complex antibodies: experience from a tertiary referral centre. J Neurol Neurosurg Psychiatry 85(6): $625-630$

Pathmanandavel K et al (2015) Antibodies to surface dopamine-2 receptor and N-methyl-D-aspartate receptor in the first episode of acute psychosis in children. Biol Psychiatry 77(6):537-547

Patil ST et al (2007) Activation of mGlu2/3 receptors as a new approach to treat schizophrenia: a randomized phase 2 clinical trial. Nat Med 13(9):1102-1107

Pearlman DM, Najjar S (2014) Meta-analysis of the association between $\mathrm{N}$-methyl-d-aspartate receptor antibodies and schizophrenia, schizoaffective disorder, bipolar disorder, and major depressive disorder. Schizophr Res 157(1-3):249-258

Peng X et al (2015) Cellular plasticity induced by anti-alpha-amino-3hydroxy-5-methyl-4-isoxazolepropionic acid (AMPA) receptor encephalitis antibodies. Ann Neurol 77(3):381-398

Perogamvros L, Schnider A, Leemann B (2012) The role of NMDA receptors in human eating behavior: evidence from a case of antiNMDA receptor encephalitis. Cogn Behav Neurol 25(2):93-97

Petit-Pedrol M et al (2014) Encephalitis with refractory seizures, status epilepticus, and antibodies to the GABAA receptor: a case series, characterisation of the antigen, and analysis of the effects of antibodies. Lancet Neurol 13(3):276-286

Pettingill $\mathrm{P}$ et al (2015) Antibodies to GABAA receptor alpha1 and gamma2 subunits: clinical and serologic characterization. Neurology 84(12):1233-1241
Piepgras J et al (2015) Anti-DPPX encephalitis: Pathogenic effects of antibodies on gut and brain neurons. Neurology

Pilowsky LS et al (2006) First in vivo evidence of an NMDA receptor deficit in medication-free schizophrenic patients. Mol Psychiatry 11(2):118-119

Pinatel D et al (2015) Inhibitory axons are targeted in hippocampal cell culture by anti-Caspr2 autoantibodies associated with limbic encephalitis. Front Cell Neurosci 9:265

Planaguma J et al (2015) Human N-methyl D-aspartate receptor antibodies alter memory and behaviour in mice. Brain 138(Pt 1):94-109

Pollak TA et al (2014) Prevalence of anti-N-methyl-D-aspartate (NMDA) receptor [corrected] antibodies in patients with schizophrenia and related psychoses: a systematic review and meta-analysis. Psychol Med 44(12):2475-2487

Prasad KM et al (2011) Progressive gray matter loss and changes in cognitive functioning associated with exposure to herpes simplex virus 1 in schizophrenia: a longitudinal study. Am J Psychiatry 168(8):822-830

Pruss $\mathrm{H}$ et al (2012a) IgA NMDA receptor antibodies are markers of synaptic immunity in slow cognitive impairment. Neurology 78(22):1743-1753

Pruss $\mathrm{H}$ et al (2012b) N-methyl-D-aspartate receptor antibodies in herpes simplex encephalitis. Ann Neurol 72(6):902-911

Pruss $\mathrm{H}$ et al (2014) Limbic encephalitis with mGluR5 antibodies and immunotherapy-responsive prosopagnosia. Neurology 83(15): 1384-1386

Ramberger M et al (2015) Comparison of diagnostic accuracy of microscopy and flow cytometry in evaluating N-methyl-D-aspartate receptor antibodies in serum using a live cell-based assay. PLoS One 10(3):e0122037

Rodriguez Cruz PM et al (2015) Use of cell-based assays in myasthenia gravis and other antibody-mediated diseases. Exp Neurol 270:66-71

Rubio MD, Drummond JB, Meador-Woodruff JH (2012) Glutamate receptor abnormalities in schizophrenia: implications for innovative treatments. Biomol Ther (Seoul) 20(1):1-18

Schizophrenia Working Group of the Psychiatric Genomics, C (2014) Biological insights from 108 schizophrenia-associated genetic loc. Nature 511(7510):421-427

Schretlen DJ et al (2010) Neuroanatomic and cognitive abnormalities related to herpes simplex virus type 1 in schizophrenia. Schizophr Res 118(1-3):224-231

Shirts BH et al (2008) Antibodies to cytomegalovirus and Herpes Simplex Virus 1 associated with cognitive function in schizophrenia. Schizophr Res 106(2-3):268-274

Somers KJ et al (2011) Psychiatric manifestations of voltage-gated potassium-channel complex autoimmunity. J Neuropsychiatry Clin Neurosci 23(4):425-433

Steiner J et al (2014) Prevalence of N-methyl-D-aspartate receptor autoantibodies in the peripheral blood: healthy control samples revisited. JAMA Psychiatry 71(7):838-839

Stone JM (2011) Glutamatergic antipsychotic drugs: a new dawn in the treatment of schizophrenia? Ther Adv Psychopharmacol 1(1):5-18

Stone JM et al (2012) Ketamine effects on brain GABA and glutamate levels with 1H-MRS: relationship to ketamine-induced psychopathology. Mol Psychiatry 17(7):664-665

Striano P et al (2011) Familial temporal lobe epilepsy with psychic auras associated with a novel LGI1 mutation. Neurology 76(13):11731176

Tang C et al (2015) Voltage-gated potassium channel antibody-associated encephalitis presenting as acute psychosis: case report. J Neuropsychiatry Clin Neurosci 27(1):e68-e69

Thieben MJ et al (2004) Potentially reversible autoimmune limbic encephalitis with neuronal potassium channel antibody. Neurology 62(7):1177-1182 
Timms AE et al (2013) Support for the N-methyl-D-aspartate receptor hypofunction hypothesis of schizophrenia from exome sequencing in multiplex families. JAMA Psychiatry 70(6):582-590

Titulaer MJ et al (2013) Treatment and prognostic factors for long-term outcome in patients with anti-NMDA receptor encephalitis: an observational cohort study. Lancet Neurol 12(2):157-165

Tobin WO et al (2014) DPPX potassium channel antibody: frequency, clinical accompaniments, and outcomes in 20 patients. Neurology 83(20):1797-1803

Ulusoy C et al (2012) Comparison of the cytokine profiles of patients with neuronal-antibody-associated central nervous system disorders. Int J Neurosci 122(6):284-289

Varley J, Vincent A, Irani SR (2015) Clinical and experimental studies of potentially pathogenic brain-directed autoantibodies: current knowledge and future directions. J Neurol 262(4):1081-1095

Wang $\mathrm{H}$ et al (2011) Antibodies to infectious agents and the positive symptom dimension of subclinical psychosis: The TRAILS study. Schizophr Res 129(1):47-51

Wei YC et al (2013) Rapid progression and brain atrophy in anti-AMPA receptor encephalitis. J Neuroimmunol 261(1-2):129-133

Wiedholz LM et al (2008) Mice lacking the AMPA GluR1 receptor exhibit striatal hyperdopaminergia and 'schizophrenia-related' behaviors. Mol Psychiatry 13(6):631-640
$\mathrm{Xu}$ CL et al (2011) Anti-N-methyl-D-aspartate receptor encephalitis with serum anti-thyroid antibodies and IgM antibodies against EpsteinBarr virus viral capsid antigen: a case report and one year follow-up. BMC Neurol 11:149

Yolken RH, Torrey EF (2008) Are some cases of psychosis caused by microbial agents? A review of the evidence. Mol Psychiatry 13(5): 470-479

Zandi MS et al (2011) Disease-relevant autoantibodies in first episode schizophrenia. J Neurol 258(4):686-688

Zandi MS et al (2014) Immunotherapy for patients with acute psychosis and serum N-Methyl D-Aspartate receptor (NMDAR) antibodies: a description of a treated case series. Schizophr Res 160(1-3):193195

Zandi MS, Lennox B, Vincent A (2015) N-methyl-D-aspartate receptor autoantibodies in psychiatric illness. Biol Psychiatry

Zerche $M$ et al (2015) Preexisting serum autoantibodies against the NMDAR subunit NR1 modulate evolution of lesion size in acute ischemic stroke. Stroke 46(5):1180-1186

Zhang Q et al (2012) Suppression of synaptic plasticity by cerebrospinal fluid from anti-NMDA receptor encephalitis patients. Neurobiol Dis 45(1):610-615 